in vivo $35: 3045-3052(2021)$

doi:10.21873/invivo.12600

Review

\title{
Adamantinoma: An Updated Review
}

\author{
DIMITRIOS N. VARVAROUSIS ${ }^{1}$, GEORGIOS P. SKANDALAKIS ${ }^{2}$, ALEXANDRA BARBOUTI $^{3}$, \\ GEORGIOS PAPATHANAKOS ${ }^{4}$, PANAGIOTIS FILIS ${ }^{5}$, KOSTAS TEPELENIS $^{6}$, \\ AIKATERINI KITSOULI ${ }^{7}$, PANAGIOTIS KANAVAROS ${ }^{3}$ and PANAGIOTIS KITSOULIS ${ }^{3}$ \\ ${ }^{1}$ Medical School, University of Ioannina, Ioannina, Greece; \\ ${ }^{2}$ Department of Neurosurgery, Icahn School of Medicine at Mount Sinai, New York City, NY, U.S.A.; \\ ${ }^{3}$ Department of Anatomy - Histology-Embryology, University of Ioannina, Ioannina, Greece; \\ ${ }^{4}$ Intensive Care Unit, University Hospital of Ioannina, Ioannina, Greece; \\ ${ }^{5}$ Medical School, University of Ioannina, Ioannina, Greece; \\ ${ }^{6}$ Department of Surgery, University Hospital of Ioannina, Ioannina, Greece; \\ ${ }^{7}$ University of Ioannina, Ioannina, Greece
}

\begin{abstract}
Adamantinoma is a biphasic tumor, with a low potential for malignancy, characterized by clusters of epithelial cells surrounded by a relatively bland spindle-cell osteofibrous component. The aim of the present study was to review the updated data regarding epidemiology; pathogenesis; clinical presentation; radiological, histopathological and ultrastructural findings; and treatment options of adamantinoma. In X-ray, it is usually seen as an eccentric and sometimes central, lobular, lytic lesion with sclerotic margins of overlapping radiolucency, and a characteristic 'soap-bubble' appearance. Magnetic resonance imaging seems to be the most appropriate examination for differential diagnosis between adamantinoma and other skeletal tumors. Histologically, adamantinoma is identified as classic adamantinoma or osteofibrous-like adamantinoma. Classic adamantinoma is classified into four patterns of growth: Basaloid, tubular, spindle cell, and squamous. The preferable treatment of this tumor type is en bloc resection within wide operative margins, which may include suspicious regional lymph nodes, with limb reconstruction and limb salvage.
\end{abstract}

According to the definition of the World Health Organization, adamantinoma is a miscellaneous malignant biphasic tumor

This article is freely accessible online.

Correspondence to: Dimitrios Varvarousis, MD, Ph.D., 49 Valaoritou St, Ioannina, 45333, Greece. Mobile: +30 6972296200, e-mail: dimvarvar@gmail.com

Key Words: Adamantinoma, diagnosis, treatment, review. and its characteristics are clusters of epithelial cells surrounded by a relatively bland spindle-cell osteofibrous component ( 1 , 2 ). It is a tumor with low frequency (as it occurs in less than $0.5 \%$ of all primary skeletal tumors), in terms of age most often developing between the age of 20 and 50 years, and it is more common in men. It may be located in several bones; however, the mid shaft of the tibia, with or without fibula involvement, is its most common location (3-5). The main symptom reported by patients is pain (6). Treatment of adamantinoma includes extensive resection and reconstruction of bone defect with the use of autograft, allograft, bone transport, and endoprosthesis (7).

In our previous article, we presented the epidemiological, clinical, radiological and pathological features as well as treatment options of adamantinoma (4). The aim of the present study was to review the updated data regarding history, incidence, epidemiology, origin and pathogenesis, clinical features, as well as radiological, histopathological and ultrastructural findings, new treatment strategies and prognosis of adamantinoma.

\section{The History of Adamantinoma}

Although adamantinoma is an unusual bone tumor, its origin has been debated for almost a century. The term adamantinoma comes from the ancient Greek word adamantinos, which means very hard, as the root word adamas means diamond. The first reported case of a primary skeletal tumor with epithelial characteristics, observed in the ulna, was by Maier (8) in 1900, while in 1913, Fischer (9), a physician from Germany, called this tumor 'adamantinoma' as he observed that during embryonic development adamantine 
epithelium was located in both the tibia and intraoral enamel. Lederer and Sinclair (10) and Naji et al. (11) suggested that this type of tumor has a synovial origin. However, in 1957, Changus et al. presented the first evidence for the origin of adamantinoma, suggesting that this tumor may have originated from vascular tissue, and could therefore belong to angioblastomas (12). In addition, Llombart-Bosch and OrtunoPacheco also supported the previous theory, based on their ultrastructural studies, which showed that adamantinoma cells have basement membranes, microvilli and tonofibrils forming desmosomes, which are necessary for attachments between cells (13). In 1958, Jaffe reported that the origin of adamantinoma was from epithelial cells (14). Since then, several researchers have used immunohistochemistry to demonstrate that adamantinoma cells are keratin-positive, suggesting their epithelial origin (15), while most of them agree that there was a trapping of skin epithelium during the fetal period. This is reinforced by the fact that the skin is very close to the anterior border of the tibia and for this reason the tibia is the most common location of such tumors (16). Researchers have used ultrastructural studies, electron microscopy and immunohistochemistry to demonstrate that adamantinoma cells are keratin-positive, suggesting their epithelial origin $(15,17)$. Recently, there has been discussion about the relationship between adamantinoma and osteofibrous dysplasia, in regard to diagnosis and possible treatment methods which could be applied (3).

\section{Incidence}

Adamantinoma is a very rare, low-grade, slow-growing malignant tumor representing less than $0.5 \%$ of all primary skeletal tumors $(0.33-0.48 \%)(4,18)$. Regarding gender, it is found more often in men, with a ratio of five to four (3, $4,6,16)$. Commonly affected patients are those between the age of 20 to 50 years; although adamantinoma presents earlier in females, more specifically between 11 and 30 years old, while in males between 20 to 50 years, although the range of ages is from 3 to 86 years $(19,20)$. However, the tumor is rare in childhood (21). Adamantinoma is divided into two types: classic adamantinoma, where the mean patient's age is about 40 years, and differentiated adamantinoma, where the patients are up to 20 years old (22). In addition, it is possible the true prevalence of adamantinoma is underestimated, as in previous years, these tumors might have been confused with osteofibrous or fibrous dysplasia (23). From all the reported cases, 97\% were described in long tubular bones, mostly in the diaphyses; adamantinoma rarely forms more than one or two foci (4). Its most common location is in the tibia (80-85\%), less often it is found in humerus, ulna, radius, femur, fibula and rarely in the spine, ribs, carpal or metatarsal bones or calcaneum (24-30).

\section{Origin and Pathogenesis}

As already mentioned, adamantinoma is a biphasic tumor, usually consisting of epithelial cells that stain positively for keratins 14 and 19 inside spindle-celled fibrous tissue (20); it is then a tumor of epithelial origin. In recent years, several hypotheses have been made regarding the origin of this tumor type. Fischer supported the notion of congenital epithelial cell implantation (9), while other researchers supported traumatic implantation $(31,32)$ or articular origin $(10,11)$. To this day, the pathogenesis of this tumor type is still debated but the prevailing theory is that during embryonic development, the skin basal epithelium is displaced and is supported by the predominant involvement of the anterior tibia because there the bone formed by cartilage is located closer to the surface of the skin (16). In a recent immunohistochemical study of the extracellular matrix of adamantinoma, it is stated that a mesenchymalepithelial transformation was responsible for the origin of the epithelial component, as it might have come from the fibrous component of the tumor $(23,33)$. The main histological patterns of classic adamantinoma include basaloid, tubular, spindle-cell and squamous patterns. On the other hand, differentiated adamantinoma presents as osteofibrous dysplasia-like, regressive, juvenile and intracortical (20).

\section{Clinical Features}

Most authors agree that the first symptoms of adamantinoma are swelling and pain (reported up to $72 \%$ of patients), which may be accompanied by palpable bulge, more often on the anterior surface of the tibia (19). However, the initial symptoms are non-specific and depend on the anatomical location of the lesion and its extent. Thirty percent of patients may live with the above symptoms for many years, 5 years or more, without proceeding to a medical examination. This tumor causes pathological fracture in 16$23 \%$ of patients (34), while the presence of trauma has been reported in about $25 \%$ to $60 \%$ of cases $(5,34)$. Adamantinoma is a malignant tumor and can metastasize, mainly to the lungs and adjacent lymph nodes. According to the medical literature, two cases of paraneoplastic hypercalcaemia have been reported, which were associated with pulmonary metastasis of the tumor (35); when there is a spinal localization, neurological symptoms can be manifested (36).

\section{Radiological Features}

Radiographic imaging of adamantinoma is important for its diagnosis (4). On plain X-ray (Figure 1), it usually appears as an eccentric and sometimes central, lobular lytic lesion, with sclerotic margins of overlapping radiolucency, with 


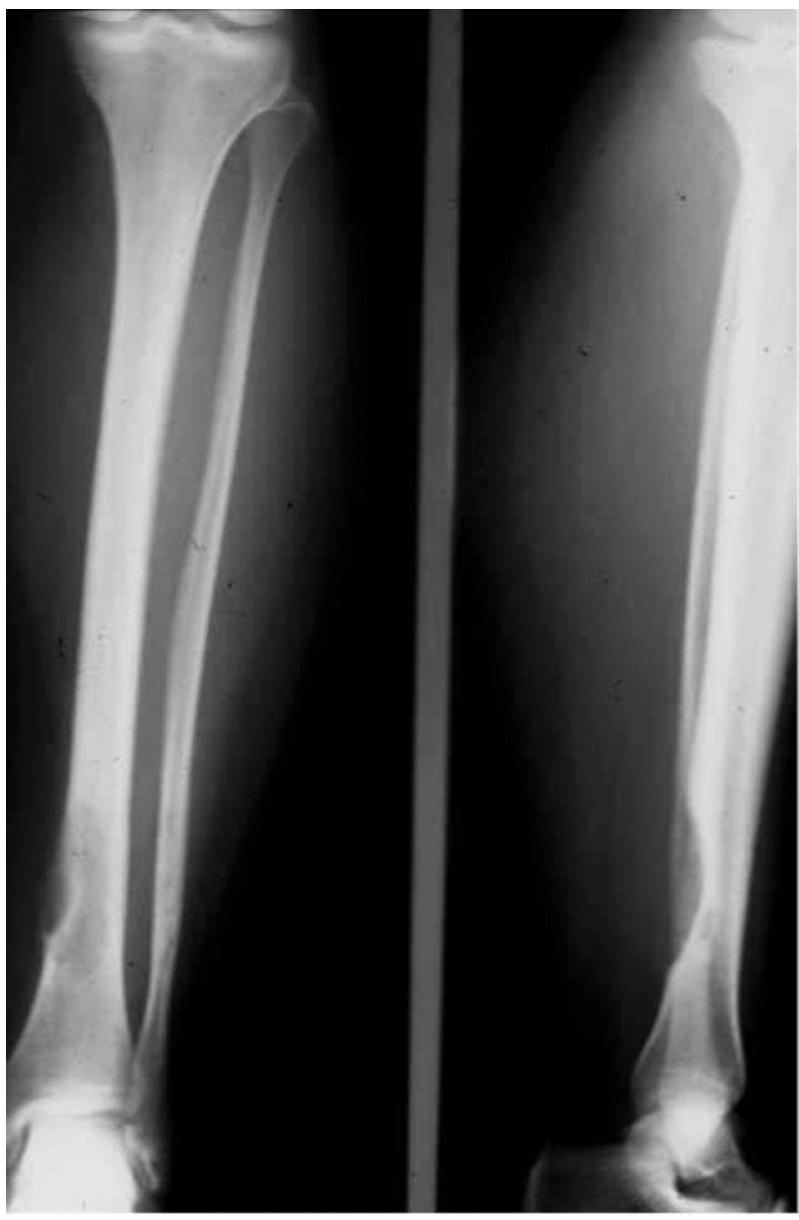

Figure 1. Radiological features of adamantinoma. X-Rays revealed a lytic lesion in the medial surface of the distal third of the right tibia.

poor or sharp delination, in the two distal thirds of the diaphysis or metaphysic of a long bone (16). Adamantinoma is usually appeared with a characteristic 'soap-bubble' appearance; due to aforementioned multifocal radiolucencies which are surrounded by ring-shaped densities. When a pathological fracture exists, then a periosteal reaction may also be present. The tumor is usually inside the cortex, although in about $15 \%$ of cases it may exit from the cortex and expand into the nearby soft tissues (21). Other characteristics of the tumor are its size, which on average it is about $11 \mathrm{~cm}$, and its longitudinal orientation. Concerning its appearance on X-ray, adamantinoma has to be distinguished from osteofibrous and fibrous dysplasia. The radiological appearance of the above lesions may be similar, therefore it is sometimes difficult to distinguish amantinoma from them (37). However, location in the diaphysis, extension towards the bone marrow, single or multiple nodular lesions in one or more foci, and intense and

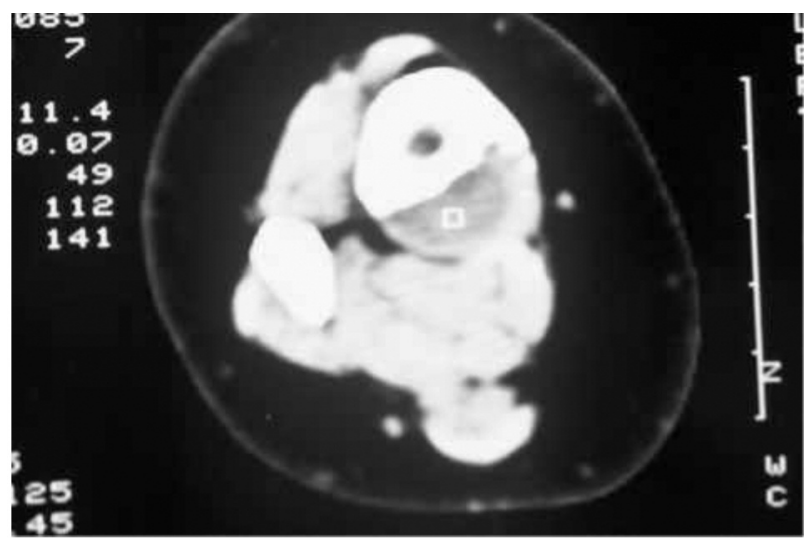

Figure 2. Computed tomography of adamantinoma showed a lytic area in the distal third of the tibia with a very thin cortex, but without penetration of the cortex.

homogeneous enhancement are familiar signs of adamantinoma, while dysplasias are characterized by cortical involvement without canal extension (16). Computed tomography (Figure 2) more accurately shows the osteolytic formation, the involvement of the cortex and tumor extension to the nearby soft tissues, while if can also reveal pulmonary metastases, without detecting intraosseous tumor extension (38). Magnetic resonance imaging (MRI), as it is specialized for revealing lesions of soft tissues, seems to be the most appropriate examination for the differential diagnosis between adamantinoma and other skeletal tumors, such as fibrous or osteofibrous dysplasia, osteosarcoma, Ewing's sarcoma and metastatic carcinoma (39, 40). Adamantinoma demonstrates low signal intensity on T1weighted spin-echo images and high signal intensity on T2weighted images but the above findings are not specific as they can also be seen in other tumors. MRI may reveal expansion of the tumor inside the medullary cavity or in adjacent tissues, which is essential for the accurate determination of tumor boundaries and the preoperative planning for appropriate surgery (16). Two morphological patterns on MRI have been described, a solitary lobulated focus and a pattern of multiple small nodules in one or more foci (39). Regarding nuclear medicine imaging, adamantinoma is characterized by increased blood flow, increased blood concentration and accumulation of technetium-99m in the tumoraI region, while a bone scan may reveal involvement of the fibula (41).

\section{Histopathological Features}

Regarding histopathology, adamantinoma is distinguished into osteofibrous-like adamantinoma and classic adamantinoma, 
although it generally presents many histological types (42). Osteofibrous-like adamantinoma has a better outcome than classic adamantinoma (43). Classic adamantinoma is classified into four patterns of growth namely basaloid, tubular, spindlecell and squamous (22). The basaloid pattern consists of solid masses of basaloid cells. The tubular pattern displays a line of cuboidal epithelial cells with central discohesion. The spindlecell pattern exhibits uniform spindling; although it displays staining for cytokeratin, which indicates a possibility of sarcomatoid carcinoma, the differential diagnosis is not challenging due to the fact that adamantinoma does not exhibit significant cytological atypia in contrast to carcinoma. The squamous pattern may resemble squamous carcinoma, but once again, the atypia escorting carcinoma solves this matter of differential diagnosis (42). Compared to classic adamantinoma, which has a dominant epithelial component, osteofibrous-like adamantinoma is composed mainly of osteofibrous tissue. The diagnostic criteria for osteofibrouslike adamantinoma is the predominance of the osteofibrous tissue containing small clusters of epithelial cells and cytokeratin-positive staining (43), while the diagnosis of osteofibrous-like adamantinoma versus osteofibrous dysplasia can only be achieved via detection of a small number of epithelial cells. Adamantinoma exhibits a low mitotic rate. Several studies have also shown that foci of calcification, giant cells, xanthoma and spindle cells can be found in adamantinoma $(4,23)$.

\section{Immunophenotypic Features}

Adamantinomas are immunohistochemically positive for keratins 14 and 19 (44). The epithelial component exhibits co-expression of cytokeratins 5, 14 and 19, epithelial membrane antigen and vimentin (16). The stromal component displays immunohistochemical positivity for vimentin. Adamantinomas lack the immunohistochemical expression of keratins 8 and 18, which differentiates them from many other skeletal or soft-tissue tumors (4). In addition, the immunoreactivity pattern of keratin is independent of histological subtype, although there is a notable variety in the differentiation pattern, which led to the suggestion that all subtypes of adamantinoma have a common histogenesis (16). It is remarkable that the same pattern is observed in local recurrence and metastasis, however, there are significant differences from other musculoskeletal tumors with known epithelial elements, such as chordomas and epithelioid or synovial sarcomas (44). P63 is also a reliable marker for the diagnosis of adamantinoma (40). In classic adamantinoma, immunochemistry can also detect E-, P- and N-cadherin, as well as osteonectin, but not osteopontin and osteocalcin (45). As is also seen in osteofibrous dysplasia, adamantinoma cells immunohistochemically express receptor activator of nuclear factor $\mathrm{kB}$ ligand, macrophage colony-stimulating factor and osteoclastogenic factors, which may be responsible for the osteolysis which is described in the referred lesions (46). Other researchers studied the proliferation marker Ki67, epidermal growth factor, epidermal growth factor receptor and fibroblast growth factor type 2 and concluded that the epithelial component is the primary proliferating tumor cell population capable of stimulating reactive fibrous growth (47). In another study, DNA flow cytometry and p53 immunohistochemistry were examined, in which the results were aneuploidy and significant p53 immunoreactivity only in nuclei of cells of epithelial phenotype (48). In addition, studying lung metastases, epithelial cells which were positive for cytokeratin were found in the metastases, in contrast with the osteofibrous stromal component. From the above studies, Jain et al. reported that adamantinoma contains a malignant epithelial component with a reactive osteofibrous layer, or there is a proliferating benign fibrous element where the malignant epithelial component develops (16).

\section{Ultrastructural Features}

Ultrastructural analysis reveals cell membranes with hemidesmosomes, a basal membrane encircling the epithelial, cells and perinuclear tonofilaments (49). Electron microscopy can also detect microvilli representing tubular lamina between the cells, as well as rarer desmosomes and junctions. Moreover, cells with epithelial properties can be occasionally found in the stromal tissue (4). In addition, the stromal component consists of fibroblasts and less commonly of myofibroblasts, while spindled and round-to-stellate epithelial cells mixed with fibroblasts were observed within stroma (33).

\section{Genetic Studies}

Cytogenetic studies detected trisomies of chromosomes 7, 8, 12, 19 and/or 21 in classic and osteofibrous-like adamantinoma $(50,51)$. The same aneuploidies, beside that of chromosome 19, have also been found in cases of osteofibrous dysplasia, shedding more light on the relationship between the two entities (50). The extra chromosomes are found only in the epithelial component of adamantinomas (4). Mutations of p53 revealed via immunohistochemical staining or by loss of heterozygosity analysis are also restricted to epithelial cells, underlining that the neoplastic behavior of the tumor is most probably attributed to its epithelial component (4). Adamantinoma-like Ewing sarcoma, which is a rare type of Ewing sarcoma which combines histological features of adamantinoma, can be diagnosed with molecular analysis aiming to identify the $\mathrm{t}(11 ; 22)$ Ewing sarcoma fusion protein (EWSR1-FLI1) translocation $(23,40)$, as it is difficult to diagnose with the use of other methods due to their resemblance to other more common tumors (52). Finally, in a recent study, researchers 
combined whole-exome sequencing and copy-number variation techniques and found that in $38 \%$ of adamantinomas the chromatin remodeling-related gene histone-lysine $N$-methyltransferase 2D (KMT2D) was "recurrently altered" (18).

\section{Differential Diagnosis}

Although adamantinoma is a rare tumor, it may resemble a multitude of other tumors and conditions, including $(16,53,54)$ :

- Fibrous dysplasia: Similar histological and radiological (lucent patches typically have ground glass appearance) appearance and typical location in the tibia; difficult differential diagnosis from osteofibrous dysplasia-like adamantinoma.

- Giant cell tumor: Pain with swelling; soap bubble appearance on X-ray; multinucleated giant cells on microscopy.

- Aneurysmal bone cyst: In X-ray, a well-defined radiolucent eccentric cyst; on microscopy, fibrous tissue is present.

- Unicameral bone cyst: Asymptomatic; radiolucent cyst on $\mathrm{X}$-ray; on microscopy, fibrous tissue is present.

- Chondrosarcoma: Pain; radiolucent area with central flecks of calcification on X-ray; on microscopy, lobules of highly atypical cells are apparent.

- Chondromyxoid fibroma: Asymptomatic; on X-ray, eccentric lytic lesion with well-defined sclerotic margins is seen; on microscopy, patches of myxomatous tissue with stellate cells, parts of hyaline cartilage, and fibrous tissue are noted.

- Hemangioendothelioma: Pain and swelling; on X-ray, lytic and poorly demarcated lesions with soap bubble appearance and sclerotic margins; on microscopy, solid nests of round, polygonal, or spindle-shaped cells with eosinophilic cytoplasm are found.

- Other: Like angiosarcoma, eosinophilic granuloma, epithelial metastasis, Ewing sarcoma, intraosseous synovial sarcoma, nonossifying fibromas, osteomyelitis

\section{Treatment}

Generally, adamantinomas are slowly growing tumors. In the past, the treatment of choice was amputation; however, with the progress of medicine, new surgical techniques are nowadays used for reconstructions following en bloc resection of the lesion $(19,55)$. As adamantinoma is a rare tumor, in the literature there are no definitive guidelines concerning the treatment (56). Moreover, as the initial therapy is of critical importance, an attentive biopsy has to be carried out avoiding curettage. The preferable treatment of the tumor involves its en bloc resection within wide operative margins, which may include suspicious regional lymph nodes, with limb reconstruction and limb salvage (57). In addition, there are several strategies aiming to fill in the defect of the excised bone such as distraction osteogenesis, intercalary allografts, vascularised fibular autografts and custom-made prostheses or endoprosthesis $(16,17,58)$. When the tumor is located in the distal fibula, primary ankle arthrodesis can be a reasonable choice (26). Performing an amputation as a treatment of adamantinoma does not increase survival in comparison with the previous surgical techniques, however, when a local recurrence occurs or there is no other option available, amputation could be accepted. Radiation therapy and chemotherapy are considered as ineffective treatments regarding this specific tumor. The incidence of adamantinoma-related death ranges from $12 \%$ to $17 \%$ (4). Many researchers reported high 5- or 10-year survival rates after en bloc resection of the tumor with limb salvage. In a review of 70 patients, the 10-year survival rate was reported to be as high as $87.2 \%$ (59), while the 5-year survival rate was higher at $95-98.8 \%(6,23)$. The biological behavior of an adamantinoma is highly unpredictable (30) and generally recurrence presents with a more progressive behavior (20). About $15 \%$ of the patients develop metastases to the lungs and lymph nodes, although rarely is the skeleton, liver and brain affected $(1,60,61)$. Moreover, cutaneous metastasis has been reported (62), while local recurrence or distant metastases appeared even up to 36 years after diagnosis (63). Risk factors for recurrence or metastasis are a medical history reporting symptoms of less than 5 years, male gender, young age, pain at presentation, lack of squamous differentiation and increased epithelium-to-stroma ratio (64). When adamantinoma metastasizes the prognosis is poor, although multikinase inhibitors, such as sunitinib, may prolong survival (65). It is important to adopt a long-term follow-up as early diagnosis is essential for the treatment and prognosis of recurrence and metastases (43).

\section{Conclusion}

Adamantinoma is a rare tumor of the long bones, and the tibia is the most common manifestation. Regarding histopathology, adamantinoma is distinguished into osteofibrous-like adamantinoma and classic adamantinoma, and generally is presented with many histological types. Although it belongs to the group of tumors of low malignancy, it might metastasize to lungs and to neighboring lymph nodes, while rarely to other bones, liver and brain. When adamantinoma metastasizes, the prognosis is poor. The preferable treatment of the tumor involves its en bloc resection within wide operative margins, which may include suspicious regional lymph nodes, with limb reconstruction and limb salvage. Distraction osteogenesis, intercalary allografts, vascularised fibular autografts and custom-made prostheses or endoprotheses can be used to bridge the defect of the excised bone. When a local recurrence occurs or there 
is no other option available, amputation remains an alternative. Finally, long-term follow-up is important as early diagnosis is essential for treatment and prognosis.

\section{Conflicts of Interest}

The Authors report no conflicts of interest.

\section{Authors' Contributions}

Varvarousis D: Study conception and design. Skandalakis GP: Literature search and acquisition of data. Barbouti A: Critical revision. Papathanakos G: Critical revision. Filis P: Study conception and design. Tepelenis K: Study conception and design. Kitsouli A: Draft of the work. Kanavaros P: Analysis and interpretation of data. Kitsoulis P: Final approval of the version to be published.

\section{References}

1 Fletcher CDM: WHO classification of tumours of soft tissue and bone [text]. Lyon, France, International Agency for Research on Cancer, 2013.

2 Chen J and Zhang J: Adamantinoma filling the medullary space of the tibia: A case report. Radiol Case Rep 14(11): 1330-1333, 2019. PMID: 31516648. DOI: 10.1016/j.radcr.2019.08.013

3 Holden DM, Joyce MJ and Sundaram M: Adamantinoma. Orthopedics 37(6): 362,420-362,422, 2014. PMID: 24972424. DOI: $10.3928 / 01477447-20140528-01$

4 Kitsoulis P, Charchanti A, Paraskevas G, Marini A and Karatzias G: Adamantinoma. Acta Orthop Belg 73(4): 425-431, 2007. PMID: 17939469.

5 Moon NF and Mori H: Adamantinoma of the appendicular skeleton - updated. Clin Orthop Relat Res (204): 215-237, 1986. PMID: 3514033.

6 Aytekin MN, Öztürk R and Amer K: Epidemiological study of adamantinoma from US surveillance, epidemiology, and end results program: III retrospective analysis. J Oncol 2020: 2809647, 2020. PMID: 32612653. DOI: 10.1155/2020/2809647

7 Zumárraga JP, Cartolano R, Kohara MT, Baptista AM, Dos Santos FG and de Camargo OP: Tibial adamantinoma: Analysis of seven consecutive cases in a single institution. Acta Ortop Bras 26(4): 252-254, 2018. PMID: 30210255. DOI: 10.1590/ 1413-785220182604192680

8 Maier C: Ein primares myelogenes platten epithelcarcinom der ulnabruns. Bruns Beitr Klin Chir 26: 55, 1900.

9 Fischer B: Uber ein primäres adamantinoma der tibia. Virchows Arch [B] 12: 422-441, 1913.

10 Lederer $\mathrm{H}$ and Sinclair AJ: Malignant synovioma simulating "adamantinoma of the tibia". J Pathol Bacteriol 67(1): 163-168, 1954. PMID: 13152629. DOI: 10.1002/path.1700670120

11 Naji AF, Murphy JA, Stasney RJ, Neville WE and Chrenka P: So-called adamantinoma of long bones. J Bone Joint Surg Am 46: 151-158, 1964. PMID: 14104305.

12 Changus GW, Speed JS and Stewart FW: Malignant angioblastoma of bone; a reappraisal of adamantinoma of long bone. Cancer 10(3): 540-559, 1957. PMID: 13460949. DOI: 10.1002/10970142(195705/06)10:3<540::aid-cncr2820100317>3.0.co;2-c
13 Llombart-Bosch A and Ortuño-Pacheco G: Ultrastructural findings supporting the angioblastic nature of the so-called adamantinoma of the tibia. Histopathology 2(3): 189-200, 1978. PMID: 566709. DOI: 10.1111/j.1365-2559.1978.tb01709.x

14 Jaffe HL: Tumors and tumorous conditions of the bones and joints. Lea and Febiger, Philadelphia, 1958.

15 Rosai J: Adamantinoma of the tibia. Electron microscopic evidence of its epithelial origin. Am J Clin Pathol 51(6): 786792, 1969. PMID: 5770677. DOI: 10.1093/ajcp/51.6.786

16 Jain D, Jain VK, Vasishta RK, Ranjan P and Kumar Y: Adamantinoma: a clinicopathological review and update. Diagn Pathol 3: 8, 2008. PMID: 18279517. DOI: 10.1186/1746-15963-8

17 Khan MH, Darji R, Rao U and McGough R: Leg pain and swelling in a 22-year-old man. Clin Orthop Relat Res 448: 259266, 2006. PMID: 16826129. DOI: 10.1097/01.blo.000 0195924.36103.11

18 Ali NM, Niada S, Morris MR, Brini AT, Huen D, Sumathi V and Latif F: Comprehensive Molecular Characterization of Adamantinoma and OFD-like Adamantinoma Bone Tumors. Am J Surg Pathol 43(7): 965-974, 2019. PMID: 31021853. DOI: 10.1097/PAS.0000000000001251

19 Houdek MT, Sherman CE, Inwards CY, Wenger DE, Rose PS and Sim FH: Adamantinoma of bone: Long-term follow-up of 46 consecutive patients. J Surg Oncol 118(7): 1150-1154, 2018. PMID: 30332521. DOI: 10.1002/jso.25269

20 Schwarzkopf E, Tavarez Y, Healey JH, Hameed M and Prince DE: Adamantinomatous tumors: Long-term follow-up study of 20 patients treated at a single institution. J Surg Oncol 122(2): 273-282, 2020. PMID: 32334443. DOI: 10.1002/jso.25950

21 Van Rijn R, Bras J, Schaap G, van den Berg H and Maas M: Adamantinoma in childhood: report of six cases and review of the literature. Pediatr Radiol 36(10): 1068-1074, 2006. PMID: 16906392. DOI: 10.1007/s00247-006-0272-5

22 Kumar A, Sharma R, Verma AK, Tiwari A and Mishra J: An unusual case of adamantinoma of long bone. Autops Case Rep 11: e2021276, 2021. PMID: 34249787. DOI: 10.4322/acr.2021.276

23 Hazelbag HM, Taminiau AH, Fleuren GJ and Hogendoorn PC: Adamantinoma of the long bones. A clinicopathological study of thirty-two patients with emphasis on histological subtype, precursor lesion, and biological behavior. J Bone Joint Surg Am 76(10): 1482-1499, 1994. PMID: 7929496. DOI: 10.2106/0000 4623-199410000-00008

24 Nerubay J, Chechick A, Horoszowski H and Engelberg S: Adamantinoma of the spine. A case report. J Bone Joint Surg Am 70(3): 467-469, 1988. PMID: 3346278.

25 Ulmar B, Delling G, Werner M, Huch $\mathrm{K}$ and Reichel $\mathrm{H}$ : Classical and atypical location of adamantinomas - presentation of two cases. Onkologie 29(6): 276-278, 2006. PMID: 16783903. DOI: 10.1159/000093049

26 Yoshida S, Murakami T, Suzuki K, Itou S, Watanuki M, Hosaka $\mathrm{M}$ and Hagiwara Y: Adamantinoma arising in the distal end of the fibula. Rare Tumors 9(1): 6823, 2017. PMID: 28458791. DOI: $10.4081 / \mathrm{rt} .2017 .6823$

27 Sherman GM, Damron TA and Yang Y: CD99 positive adamantinoma of the ulna with ipsilateral discrete osteofibrous dysplasia. Clin Orthop Relat Res (408): 256-261, 2003. PMID: 12616068. DOI: 10.1097/00003086-200303000-00034

28 Clarke RP, Leonard JR, von Kuster L and Wesseler TA: Adamantinoma of the humerus with early metastases and death. 
A case report with autopsy findings. Orthopedics 12(8): 11211125, 1989. PMID: 2671964.

29 Chandrasekar CR, Mohammed R, Rafalla AA and Grimer RJ: Adamantinoma of the calcaneum - a case report. Foot (Edinb) 19(1): 58-61, 2009. PMID: 20307451. DOI: 10.1016/j.foot.2008. 09.004

30 Cao K, Susa M, Watanabe I, Nishimoto K, Horiuchi K, Sasaki A, Hayashi Y, Emoto K, Kameyama K, Nakamura M, Matsumoto $\mathrm{M}$ and Morioka $\mathrm{H}$ : Adamantinoma of the distal femur diagnosed 5 years after initial surgery: a case report. J Med Case Rep 10(1): 185, 2016. PMID: 27337984. DOI: 10.1186/s13256-016-0974-8

31 Dockerty $M$ and Meyerding $H$ : Adamantinoma of the tibia. Journal of the American Medical Association 119(12): 932, 2016. DOI: $10.1001 /$ jama.1942.02830290012005

32 Ryrie BJ: Adamantinoma of the tibia: Aetiology and pathogenesis. Br Med J 2(3752): 1000-1020.1, 1932. PMID: 20777206. DOI: $10.1136 / \mathrm{bmj} .2 .3752 .1000$

33 Sarita-Reyes CD, Greco MA and Steiner GC: Mesenchymalepithelial differentiation of adamantinoma of long bones: an immunohistochemical and ultrastructural study. Ultrastruct Pathol 36(1): 23-30, 2012. PMID: 22292734. DOI: 10.3109/01913123.2011.631725

34 Schutgens EM, Picci P, Baumhoer D, Pollock R, Bovée JVMG, Hogendoorn PCW, Dijkstra PDS, Rueten-Budde AJ, Jutte PC, Traub F, Leithner A, Tunn PU, Funovics P, Sys G, San-Julian M, Schaap GR, Dürr HR, Hardes J, Healey J, Capanna R, Biau D, Gomez-Brouchet A, Wunder J, Cosker TDA, Laitinen MK, Niu X, Kostiuk V, van de Sande MAJ and Adamantinoma Research Group: Surgical outcome and oncological survival of osteofibrous dysplasia-like and classic adamantinomas: an international multicenter study of 318 cases. J Bone Joint Surg Am 102(19): 1703-1713, 2020. PMID: 33027124. DOI: 10.2106/JBJS.19.01056

35 Van Schoor JX, Vallaeys JH, Joos GF, Roels HJ, Pauwels RA and Van Der Straeten ME: Adamantinoma of the tibia with pulmonary metastases and hypercalcemia. Chest 100(1): 279281, 1991. PMID: 1647939. DOI: 10.1378/chest.100.1.279

36 Dini LI, Mendonça R, Adamy CA and Saraiva GA: Adamantinoma of the spine: case report. Neurosurgery 59(2): E426; discussion E426, 2006. PMID: 16883154. DOI: 10.1227/01.NEU.0000223497.06588.4A

37 Bethapudi S, Ritchie DA, Macduff E and Straiton J: Imaging in osteofibrous dysplasia, osteofibrous dysplasia-like adamantinoma, and classic adamantinoma. Clin Radiol 69(2): 200-208, 2014. PMID: 24199850. DOI: 10.1016/j.crad.2013.09.011

38 Chelli bouaziz M, Meherzi M, Jlassi H, Nouri H, Chaabane S, Daghfous M, Karray S and Ladeb M: Adamantinoma of the tibia: a clinicoradiologic study of four cases. European Journal of Orthopaedic Surgery \& Traumatology 19(6): 427-432, 2019. DOI: $10.1007 /$ s00590-009-0448-4

39 Van der Woude HJ, Hazelbag HM, Bloem JL, Taminiau AH and Hogendoorn PC: MRI of adamantinoma of long bones in correlation with histopathology. AJR Am J Roentgenol 183(6): 1737-1744, 2004. PMID: 15547221. DOI: 10.2214/ajr.183.6. 01831737

40 Bohndorf K, Nidecker A, Mathias K, Zidkova H, Kaufmann H and Jundt G: [The radiological findings in adamantinoma of the long tubular bones]. Rofo 157(3): 239-244, 1992. PMID: 1391818. DOI: $10.1055 / \mathrm{s}-2008-1033006$
41 Lucas DR: Dahlin's Bone Tumors: General Aspects and Data on 11,087 Cases. Fifth Edition. Lippincott-Raven, Philadelphia, 1996.

42 Dashti NK, Howe BM, Inwards CY, Fritchie KJ and Carter JM: High-grade squamous cell carcinoma arising in a tibial adamantinoma. Hum Pathol 91: 123-128, 2019. PMID: 30496800. DOI: 10.1016/j.humpath.2018.11.018

43 Deng Z, Gong L, Zhang Q, Hao L, Ding Y and Niu X: Outcome of osteofibrous dysplasia-like versus classic adamantinoma of long bones: a single-institution experience. J Orthop Surg Res 15(1): 268, 2020. PMID: 32677983. DOI: 10.1186/s13018-02001769-5

44 Hazelbag HM, Fleuren GJ, vd Broek LJ, Taminiau AH and Hogendoorn PC: Adamantinoma of the long bones: keratin subclass immunoreactivity pattern with reference to its histogenesis. Am J Surg Pathol 17(12): 1225-1233, 1993. PMID: 7694513. DOI: $10.1097 / 00000478-199312000-00003$

45 Maki $\mathrm{M}$ and Athanasou N: Osteofibrous dysplasia and adamantinoma: correlation of proto-oncogene product and matrix protein expression. Hum Pathol 35(1): 69-74, 2004. PMID: 14745727. DOI: 10.1016/j.humpath.2003.07.008

46 Taylor RM, Kashima TG, Ferguson DJ, Szuhai K, Hogendoorn PC and Athanasou NA: Analysis of stromal cells in osteofibrous dysplasia and adamantinoma of long bones. Mod Pathol 25(1): 5664, 2012. PMID: 21983933. DOI: 10.1038/modpathol.2011.141

47 Bovée JV, van den Broek LJ, de Boer WI and Hogendoorn PC: Expression of growth factors and their receptors in adamantinoma of long bones and the implication for its histogenesis. J Pathol 184(1): 24-30, 1998. PMID: 9582523. DOI: 10.1002/(SICI)10969896(199801)184:1<24::AID-PATH952>3.0.CO;2-W

48 Hazelbag HM, Fleuren GJ, Cornelisse CJ, van den Broek LJ, Taminiau AH and Hogendoorn PC: DNA aberrations in the epithelial cell component of adamantinoma of long bones. Am J Pathol 147(6): 1770-1779, 1995. PMID: 7495301.

49 Resnick D: Tumours and tumour-like lesions of bone : Imaging and pathology of specific lesions. In: Diagnosis of Bone and Joint Disorders. Third Edition. Resnick D (ed.). Saunders, Philadelphia, PA, pp. 3882-3884, 1995.

50 Sozzi G, Miozzo M, Di Palma S, Minelli A, Calderone C, Danesino C, Pastorino U, Pierotti MA and Della Porta G: Involvement of the region $13 \mathrm{q} 14$ in a patient with adamantinoma of the long bones. Hum Genet 85(5): 513-515, 1990. PMID: 2227936. DOI: $10.1007 / \mathrm{BF} 00194227$

51 Hazelbag HM, Wessels JW, Mollevangers P, van den Berg E, Molenaar WM and Hogendoorn PC: Cytogenetic analysis of adamantinoma of long bones: further indications for a common histogenesis with osteofibrous dysplasia. Cancer Genet Cytogenet 97(1): 5-11, 1997. PMID: 9242211. DOI: 10.1016/s0165-4608(96)00308-1

52 Bishop JA, Alaggio R, Zhang L, Seethala RR and Antonescu CR: Adamantinoma-like Ewing family tumors of the head and neck: a pitfall in the differential diagnosis of basaloid and myoepithelial carcinomas. Am J Surg Pathol 39(9): 1267-1274, 2015. PMID: 26034869. DOI: 10.1097/PAS.0000000000000460

53 Horvai A, Dashti NK, Rubin BP, Kilpatrick SE, Rudzinski ER, Lopez-Terrada D, Hubley MB, Davis JL and Fritchie K: Genetic and molecular reappraisal of spindle cell adamantinoma of bone reveals a small subset of misclassified intraosseous synovial sarcoma. Mod Pathol 32(2): 231-241, 2019. PMID: 30206413. DOI: $10.1038 / \mathrm{s} 41379-018-0115-6$ 
54 Rooper LM and Bishop JA: Soft tissue special issue: Adamantinoma-like Ewing sarcoma of the head and neck: A practical review of a challenging emerging entity. Head Neck Pathol 14(1): 59-69, 2020. PMID: 31950471. DOI: 10.1007/s12105-019-01098-y

55 Papagelopoulos PJ, Mavrogenis AF, Galanis EC, Savvidou OD, Inwards $\mathrm{CY}$ and Sim FH: Clinicopathological features, diagnosis, and treatment of adamantinoma of the long bones. Orthopedics 30(3): 211-5; quiz 216-7, 2007. PMID: 17375547. DOI: 10.3928/01477447-20070301-04

56 Ii S, Tsuchiya H, Takazawa K, Minato $\mathrm{H}$ and Tomita K: Adamantinoma of the proximal femur: a case report. J Orthop Sci 9(2): 152-156, 2004. PMID: 15045543. DOI: 10.1007/ s00776-003-0753-4

57 Anoumou MN, Kouameu M, Koffi EK and Varango G: Adamantinoma of the tibia: A case report. J Orthop Case Rep 4(1): 15-17, 2014. PMID: 27298937. DOI: 10.13107/jocr.22500685.140

58 Kitsoulis P, Mantellos G and Xenakis T: Adamantinoma of the tibia: local resection and distraction osteogenesis. Acta Chir Belg 109(1): 126-129, 2009. PMID: 19341216. DOI: 10.1080/00015458. 2009.11680391

59 Qureshi AA, Shott S, Mallin BA and Gitelis S: Current trends in the management of adamantinoma of long bones. An international study. J Bone Joint Surg Am 82(8): 1122-1131, 2000. PMID: 10954102. DOI: $10.2106 / 00004623-200008000-00009$

60 Picci P, Manfrini M, Fabbri N, Gambarotti M and Vanel D: Atlas of musculoskeletal tumors and tumorlike lesions the rizzoli case archive. Cham, Springer International Publishing, 2014.
61 Schowinsky JT, Ormond DR and Kleinschmidt-DeMasters BK: Tibial adamantinoma: late metastasis to the brain. J Neuropathol Exp Neurol 74(1): 95-97, 2015. PMID: 25470349. DOI: 10.1097/NEN.0000000000000145

62 Luber AJ, Glembocki DJ, Butler DC and Patel NB: Metastatic adamantinoma presenting as a cutaneous papule. Cutis 104(1): E15-E16, 2019. PMID: 31487350.

63 De Keyser F, Vansteenkiste J, Van Den Brande P, Demedts M and Van de Woestijne KP: Pulmonary metastases of a tibia adamantinoma. Case report and review of the literature. Acta Clin Belg 45(1): 31-33, 1990. PMID: 2161603. DOI: 10.1080/17843286.1990.11718062

64 Jundt G, Remberger K, Roessner A, Schulz A and Bohndorf K: Adamantinoma of long bones. A histopathological and immunohistochemical study of 23 cases. Pathol Res Pract 191(2): 112-120, 1995. PMID: 7567680. DOI: 10.1016/S03440338(11)80560-1

65 Liman AD, Liman AK, Shields J, Englert B and Shah R: A case of metastatic adamantinoma that responded well to sunitinib. Case Rep Oncol Med 2016: 5982313, 2016. PMID: 27630780. DOI: $10.1155 / 2016 / 5982313$
Received June 3, 2021

Revised August 11, 2021

Accepted August 26, 2021 